\title{
Application of Orthopedic Dual Sliding Compression Plate(ODSCP) in High Medial Tibial Open Wedge Osteotomies
}

\author{
Seyed Salman Samani ${ }^{1}$,Amir Reza Kachooei ${ }^{1,{ }^{*}}$, Mohammad Hosein Ebrahimzadeh ${ }^{1}$, Farzad \\ Omidi Kashani ${ }^{1}$, Reza Mahdavian Naghashzargar ${ }^{1}$, Shiva Razi ${ }^{1}$ \\ ${ }^{1}$ Orthopedic and Trauma Research Center, Mashhad University of Medical Sciences, Mashhad, IR, Iran \\ ${ }^{*}$ Corresponding author: Amir Reza Kachooei, Orthopedic and Trauma Research Center, Mashhad University of Medical Sciences, Mashhad, IR, Iran. Tel: +98- \\ 5118012610, Fax:+98-5118417453, E-mail: kachoeear@mums.ac.ir.
}

\begin{abstract}
A B S T R A C T
Background: Angular deformities about the knee are one of the common disorders. High Tibial osteotomy is a way of correcting the deformity. Although the general agreement is focused toward the open wedge technique, discussion about the type of device is a subject to debate.

objectives: This current study has attempted to evaluate the results of Orthopedic Dual Sliding Compression Plate (ODSCP) in high medial open wedge osteotomies of the tibia.

Patients and Methods: In this cross-sectional study, 16 patients with genuvarum undergone high medial tibial open wedge osteotomy and fixed by Orthopedic Dual Sliding Compression Plate. At the time of the last follow up visit, Lysholm score was gathered.

Results: The mean follow-up time was $9.33 \pm 1.87$ month. The average age was $45.13 \pm 7.25$ years. Three patients were male and 13 patients were female. The lysholm score showed a significant difference before and after surgery.

Conclusions: The ODSCP has many advantages over the other type of plates. It can help the surgeon to operate with a relaxed mind and it is advisable for high tibial medial open wedge osteotomies.
\end{abstract}

Keywords: Osteotomy; Range of Motion, Articular; Genu Varum

Copyright @ 2013, Iranian Red Crescent Medical Journal; Published by Kowsar Corp.

\section{Background}

Angular deformities about the knee are one of the common disorders, which bring a person to a physician, and the usual complaint is anterior knee pain. Nevertheless, in younger generation the reason for referral can be a cosmetic one. Angular deformities were first described by Mikulicz-Radecki in 1880 . He observed that the axis of the lower extremity passes through the three joints of the hip, knee and ankle in normal individuals and the knee center deviates from this line in angular deformities of the knee (1). In this case, the medial compartment will bear the weight in genuvarum and lateral compartment will bear weight in genuvalgum, and osteoarthritis will develop in the mentioned compartment. Since the population in most countries is becoming aged, the genuvarum and consequently the resulting osteoarthritis will increase, and if the patient fulfills the criteria, high tibial osteotomy is advisable (2). High tibial osteotomy was described first by Jackson in 1958 (3) and has nowadays become a well-established surgery. Coventry, who was a pioneer in this field, has published many reports on the results of HTO (3-6). He was applying the lateral close wedge technique for osteotomy, but recently the acceptability of medial open wedge osteotomy is increasing

-Article type: Research Article; Received: 01 Oct 2012; Revised: 08 Dec 2012; Accepted: 20 Jan 2013; DOI: 10.5812/ircmj.8371

Implication for health policy/practice/research/medical education:

Open wedge osteotomy is one of the common surgeries in orthopedic surgery, but in the current literature, the device for fixation is a subject to debate. In this article we tried to show the results of this new design of plate which is going to be manufactured in Iran.

-Please cite this paper as:

Samani SS, Kachooei AR, Ebrahimzadeh MH, Omidi Kashani F, Mahdavian Naghashzargar R, Razi S. Application of Orthopedic Dual Sliding Compression Plate (ODSCP) in High Medial Tibial Open Wedge Osteotomies. Iran Red Cres Med J. 2013;15(4):335-9. DOI: 10.5812 /ircmj.8371

Copyright (C) 2013, Iranian Red Crescent Medical Journal; Published by Kowsar Corp.

This is an Open Access article distributed under the terms of the Creative Commons Attribution License (http://creativecommons.org/licenses/by/3.0), which permits unrestricted use, distribution, and reproduction in any medium, provided the original work is properly cited. 
due to lower complications like keeping the proximal tibiofibular joint and peroneal nerve intact. Besides, more accurate correction will be obtained by medial open wedge osteotomy (7). Although the general agreement is focused toward the open wedge technique, discussion about the type of device is a subject to debate, and the devices are under investigation $(1,2,8-10)$

\section{Objective}

This current study has attempted to evaluate the results of Orthopedic Dual Sliding Compression Plate(ODSCP) in high medial open wedge osteotomies of the tibia.

\section{Patients and Methods}

This clinical trial study was done in Ghaem Hospital, Mashhad, Iran. The patients with more than five degrees of knee varus, who had undergone open wedge osteotomies and fixation with ODSCP, were included in this study. The operations were done during September 2011 and February 2012 and 16 patients with 16 knees were assessed. The inclusion criteria were knee varus of more than 5 degrees, knee pain with no response to conservative treatment, appropriate weight and BMI $(<25)$ and no signs of rheumatoid arthritis. The exclusion criteria were knee flexion of less than 90 degrees, more than 20 degrees of correction needed, lateral tibial subluxation of more than $1 \mathrm{~cm}$ and three-compartment involvement. The average age of the patients was $45.13 \pm 7.25$ years and the average time to follow up was $9.33 \pm 1.87$ month.

\subsection{Plate Design}

The alloy of the current devices is steel 316 LVM, which was used to manufacture the ODSCP. This plate is consisted of two separate parts, tongue and buttonhole, which can be joined together like a rail system and can make the length of the plate adjustable (Figure 1 A-C). There are two holes above and two holes below the railing section, which are placed in a horizontal fashion to decrease the length of the plate and the length of the incision as well. The short length is one of the advantages over the other types like T-plate. The proximal part is consisted of two holes for bone screws on one side and the tongue on the other side. There are fine grooves on the anterior side of the tongue and two holes for locking screws. The distal part is consisted of two holes on one side and the buttonhole on the other side. As the locking screws compress the buttonhole on the tongue part, the buttonhole's fine grooves on the posterior side will be joined with the tongue's grooves for stability. Locking screw is the one, which locks the tongue to the buttonhole and is a short screw. The railing design makes up to $2 \mathrm{~cm}$ lengthening possible. In addition, there is a shelf portion vertically oriented on each part to be placed in the osteotomy groove, sit on the tibial cortex and holds the osteotomy site open. The design can be changed for the number of the holes and the length. So this interchangeability makes this device a modular plate.
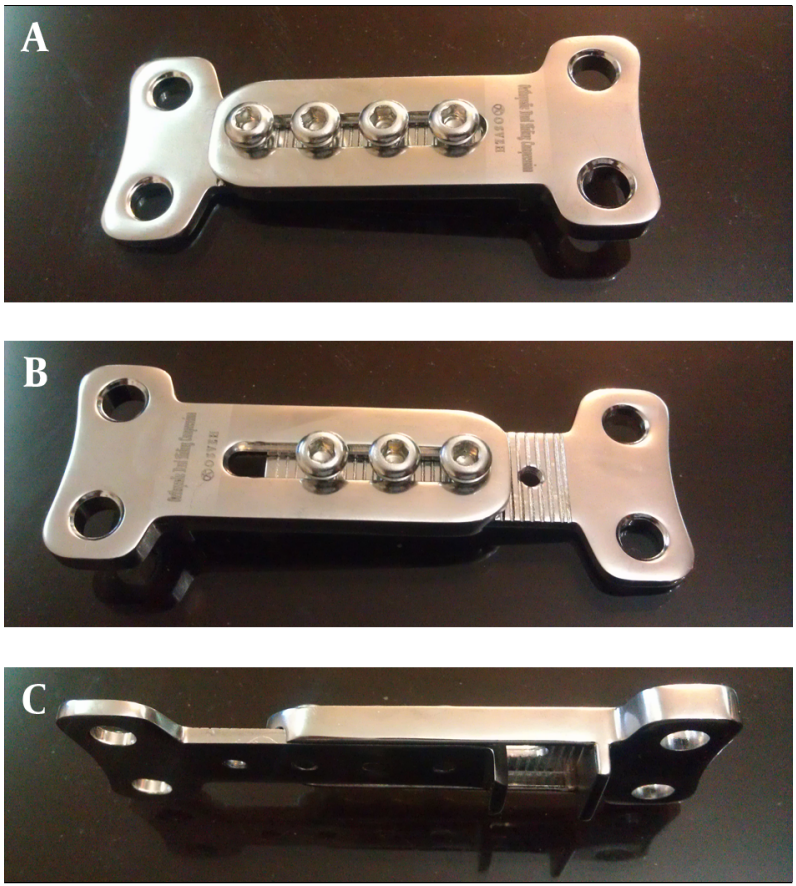

Figure 1. A-C: Design of the Orthopedic Dual Sliding Compression Plate

\subsection{Preoperative Assessment}

An AP standing hip to ankle radiography (alignment view) was done for the patients before surgery. The calculation of the angle of the deformity was done by drawing the mechanical axis of the femur from the center of the femoral head to the middle of the knee and the mechanical axis of the tibia from the middle of the plateau to the middle of the talar dome. The diameter of the opening wedge was calculated according to the formula $\mathrm{W}=$ $\mathrm{D}^{*} 0.02^{*} \mathrm{~A}$. $\mathrm{D}$ is the diameter of the tibia at the intended site of osteotomy and $\mathrm{A}$ is the angle of deformity which is calculated between the mechanical axes, and is added by 3-5 degrees for overcorrection so that the mechanical axis passes through the $62 \%$ of the tibial plateau from the medial side (11). The Lysholm score assessed patients preoperatively and all the patients signed the consent form.

\subsection{Surgical Technique}

The surgery is done on a radiolucent table in a supine position and the pneumatic tourniquet is applied. A vertical incision with a curve portion at the proximal end is placed on the medial proximal tibia and at the level of the tibial tuberosity, which is approximately $6-8 \mathrm{~cm}$ in length. Fascia and periosteum is incised limitedly in line with the incision. Patellar tendon is released from beneath to be protected and not to be cut during osteotomy. Then two parallel $2 \mathrm{~mm}$ pins are introduced in the way of the osteotomy from beneath the medial plateau hump and above 
the tuberosity toward the lateral above the proximal tibiofibular joint. After checking by the fleuroscopy, tibia was osteotomized in line with the guide pins. At this stage, without the need for any distractor, the ODSCP is inserted and screwed on the tibia so that the shelf portion is placed inside the osteotomy site. The proximal screws are cancellous type and distal screws, depending on the quality of the bone, can be cancellous or cortical ones. The locking screws in the middle are loose and the tongue and buttonhole can move along each other easily. Here, the assistant or the distrator can help to open the wedge and correct the varus to the size that was measured preoperatively, and it is check by a ruler at the time of surgery. Meanwhile the locking screws are tightened to compress the grooves of the tongue to the buttonhole. To fill the gap, tricortical bone graft is harvested from the iliac bone and inserted at the entrance of the osteotomy, and the rest of the gap can be filled by chips and cancellous allograft. The subcutaneous tissue and skin are sutured over a closed drain without evacuation (Figure $2 \mathrm{~A}-\mathrm{D}$ ).
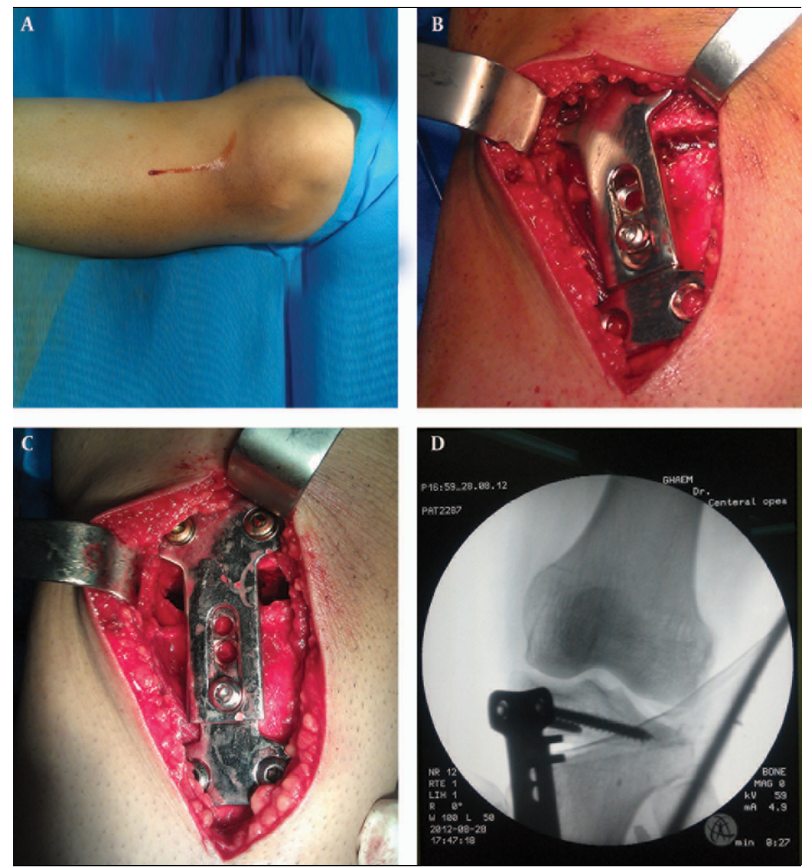

Figure 2. A-D: Surgical Technique for Application of Orthopedic Dual Sliding Compression Plate

\subsection{Postoperative Assessment and Rehabilitation}

Knee immobilizer was used for the patients after surgery and to be worn at nights. Drain was removed after 24 hours, and the patients were discharged the day after surgery. Passive and active knee range of motion and protected tip-toe weight bearing was allowed as tolerated. To decrease the prescription of NSAIDs, we ordered intravenous acetaminophen at the hospital and oral acetaminophen at home. The patient was advised to come back at two weeks for suture removal and to be introduced to a physical therapist to increase the range of motion. The next routine visits were at 6 th, 8 th and 12 th weeks after surgery and any other extra visits could be set if needed. During the visits knee examination and radiography was done. Clinical union was determined according to the absence of pain and tenderness on the palpation, and the radiographic union was determined if the ossified lines were visible in the middle of the gap. In case of clinical union, the patient was allowed to bear weight partially and in case of radiographic union in two planes, the patient was allowed to abandon the crutches and a cane being substituted, if needed. At the time of the last follow up visit, Lysholm score was gathered, radiographic union was assessed and knee was examined for the range of motion and other probable complications. Data was analyzed by SPSS software version 16 .

\section{Results}

In this clinical trial study, 16 patients and 16 knees underwent surgery. The mean follow-up time was $9.33 \pm 1.87$ month. The average age was $45.13 \pm 7.25$ years. Three patients $(18.75 \%)$ were male and 13 patients (81.25\%) were female. The plate was applied according to the above-mentioned technique. None of the patients involved with nonunion, malunion, compartment syndrome, plate failure, pes anserinus tendinitis and wound infection. The only complaint of two patients was the prominency of the plate and they desired to remove the plate after bone union. When asking if they are ready to be operated on the other knee, 13 patients (81.25\%) answered 'yes'. The result is summarized in Table 1 .

Table 1. The Summaryof Demographic Data and Pre-and Postoperative Assessment of the 16 Patients

\begin{tabular}{|ll}
\hline Demographic Data & Values \\
\hline Age, $\mathbf{y}$, Mean \pm SD & $45.13 \pm 7.25$ \\
\hline Gender, No. $(\%)$ & \\
\hline Male & $3(18.75)$ \\
\hline Female & $13(81.25)$ \\
\hline Average follow up time, months, Mean \pm SD & $9.33 \pm 1.87$ \\
\hline Average time to union, weeks, Mean \pm SD & $12.67 \pm 1.95$ \\
\hline Operation time, min, Mean \pm SD & $21.27 \pm 4.63$ \\
\hline Length of incision, $\mathbf{C m}$, Mean \pm SD & $7.6 \pm 0.82$ \\
\hline ROM, Mean \pm SD & \\
\hline Before surgery & $138 \pm 9.96$ \\
\hline After surgery & $37 \pm 8.82$ \\
\hline P value & 0.271 \\
\hline Varus angle, Mean \pm SD & \\
\hline Before surgery & $9.8 \pm 2.42$ \\
\hline After surgery & $0.2 \pm 1.20$ \\
\hline P value & $<0.001^{\mathrm{a}}$ \\
\hline Lysholm score, Mean \pm SD & \\
\hline Before surgery & $42.33 \pm 3.99$ \\
\hline After surgery & $73.93 \pm 4.18$ \\
\hline P value & $<0.001$ \\
\hline a $<0.05$ is considered significant \\
\hline
\end{tabular}




\section{Discussion}

Patients with varus deformity in their knees are advised to be undergoing corrective surgery as soon as possible $(1,12,13)$. There are two techniques of open and close wedge osteotomies. There is a tendency toward the open wedge osteotomy since it has fewer complications on the proximal tibiofibular joint and peroneal nerve. In addition, the difficulties of total knee replacement after close wedge technique are absent $(14,15)$. The main idea in most recent reports is about the type of the device with fewer complications and more advantages $(1,2$, $8-10)$. In the current study, we tried to evaluate the advantages and disadvantages of the sliding plate. To the best of our knowledge, this current study is the first study, which introduces the innovative sliding plate system for high tibial osteotomy. Staubli reported the results of a specific angular stable plate, Tomofix, in high tibial open wedge osteotomies (1). The plate was $115 \mathrm{~mm}$ long and was designed for a 10 degrees wedge opening. He evaluated 53 patients with an average age of 50 years, and the mean opening wedge was 5-20 degrees on the medial side. However, the incision was as long as the plate length, and since more screws were needed, the time of surgery would be increased (1). In a study in China on 18 patients, locking compression plate system was applied which had similar features as Tomofix (10). The average time to union was 12-16 weeks and no case of nonunion, malunion, nerve injury or plate failure was observed. Full weight bearing was started after 6-8 weeks. The mean correction of the deformity was 5.5-18 degrees. In the results of their technique, there was no difference in ROM before and after surgery, but the Lysholm score was improved significantly (10). In another study in Korea, Aescula open wedge plate was applied for fixation of the osteotomy site (2). The average time to clinical and radiographic union was $12.69 \pm 1.5$ weeks, and the incision length was $6 \mathrm{~cm}$. The radiographic measurements were improved significantly. In order to fill the osteotomy gap, they used an allograft and then a cylinder cast was applied for 3-4 weeks. No case of nonunion, malunion, compartment syndrome or nerve injury was reported (2). Likewise, in a study in Turkey, they reported the results of applying Pudu Plate, and the results were acceptable (16). Our study consisted of 16 patients with an average varus deformity of $9.8 \pm 2.42$ degrees who undergone high tibial medial open wedge osteotomy (HTMOWO) and fixation with ODSCP. The average time to union was $12.67 \pm 1.95$ weeks. The important point in designing this plate is its versatility and adjustability since the two components have a sliding feature and they can be modular. The other advantages of ODSCP over the other types are as follows; first, the short length of the plate needs short incision, which is important for cosmetic reasons. Second, more precise wedge can be opened according to the pre- and perioperative measurement. Third, in the previously mentioned reports, the distractor should be placed first to open the wedge and the plate should be inserted beside the distractor while it holds the wedge open which makes it difficult in a small space and the plate position follows the distractor position. This may lead to correction failure. However, with ODSCP, the plate is inserted at first and if needed the distractor can be placed. Otherwise, the gap can be opened manually. Forth, there is a risk for plateau fracture and extension of the osteotomy line into the articular surface if distractor be placed and forced toward the above side $(16,17)$. In applying ODSCP, the plate with long cancellous screws are inserted beneath the plateaus at first which can act as a lever for the whole surface of tibial plateau and moves it as one piece during distraction. Fifth, since the plate is inserted before distraction, the potential risk of translation or rotation will be omitted. Sixth, the time of the surgery is short due to the straightforward technique. Seventh, if any mistake in angle correction was detected after plate fixation, there is no need to remove the bone screws in order to correct the error. The only thing is needed is to loosen the small locking screws and adjust the sliding system again. According to the abovementioned advantages, the ODSCP can help the surgeon to operate with a relaxed mind and it is advisable for high tibial medial open wedge osteotomies. However, we suggest longer follow up studies with larger number of patients to compare different devices and techniques.

\section{Acknowledgements}

The authors would like to appreciate the Osveh Company for its contribution in manufacturing the plates.

\section{Authors' Contribution}

Kachooei and Samani developed and patented the idea of ODSCP. Kachooei, Samani, Ebrahimzadeh , Omidi collected the data and did the surgeries. Kachooei and Samani wrote the first draft. Mahdavian and Razi analysed and interpreted the data and did the final check of the article and translation.

\section{Financial Disclosure}

Although two authors own the patent of the plate, there was no conflict of interest since the article does not have any advantages/benefits for authors except explaining the experience in applying this new design of plate.

\section{Financial Support}

There was no financial support for this project.

\section{References}

1. Staubli AE, Jacob HA. Evolution of open-wedge high-tibial osteotomy: experience with a special angular stable device for internal fixation without interposition material. Int Orthop. 2010;34(2):167-72

2. Lee SC, Jung KA, Nam CH, Jung SH, Hwang SH. The short-term follow-up results of open wedge high tibial osteotomy with using an Aescula open wedge plate and an allogenic bone graft: the 
minimum 1-year follow-up results. Clin Orthop Surg. 2010;2(1):47-54

3. Coventry MB. Osteotomy about the knee for degenerative and rheumatoid arthritis. J Bone Joint Surg Am.1973;55(1):23-48

4. Coventry MB. Proximal tibial osteotomy. Orthop Rev. 1988;17(5):456-8

5. Coventry MB. Osteotomy of the upper portion of the tibia for degenerative arthritis of the knee. A preliminary report. 1965. Clin Orthop Relat Res. 1989;(248):4-8

6. Coventry MB, Ilstrup DM, Wallrichs SL. Proximal tibial osteotomy. A critical long-term study of eighty-seven cases. J Bone Joint Surg Am. 1993;75(2):196-201

7. Dowd GS, Somayaji HS, Uthukuri M. High tibial osteotomy for medial compartment osteoarthritis. Knee. 2006;13(2):87-92

8. Gunes T, Sen C, Erdem M. Tibial slope and high tibial osteotomy using the circular external fixator. Knee Surg Sports Traumatol Arthrosc. 2007;15(2):192-8

9. Koshino T, Morii T, Wada J, Saito H, Ozawa N, Noyori K. High tibial osteotomy with fixation by a blade plate for medial compartment osteoarthritis of the knee. Orthop Clin North Am. 1989;20(2):227-43

10. Zhang HN, Zhang J, Lv CY, Leng P, Wang YZ, Wang XD, et al. Modified biplanar open-wedge high tibial osteotomy with rigid locking plate to treat varus knee. J Zhejiang Univ Sci B. 2009;10(9):689-95
11. Dugdale TW, Noyes FR, Styer D. Preoperative planning for high tibial osteotomy. The effect of lateral tibiofemoral separation and tibiofemoral length. Clin Orthop Relat Res. 1992;(274):248-64

12. Amis AA. Biomechanics of high tibial osteotomy. Knee Surg Sports Traumatol Arthrosc. 2013;21(1):197-205

13. Odenbring S, Tjornstrand B, Egund N, Hagstedt B, Hovelius L, Lindstrand A, et al. Function after tibial osteotomy for medial gonarthrosis below aged 50 years. Acta Orthop Scand. 1989;60(5):527-31

14. Flierl S, Sabo D, Hornig K, Perlick L. Open wedge high tibial osteotomy using fractioned drill osteotomy: a surgical modification that lowers the complication rate. Knee Surg Sports Traumatol Arthrosc. 1996;4(3):149-53

15. Noda T, Yasuda S, Nagano K, Takahara Y, Namba Y, Inoue H. Clinico-radiological study of total knee arthroplasty after high tibial osteotomy. J Orthop Sci. 2000;5(1):25-36

16. Asik M, Sen C, Kilic B, Goksan SB, Ciftci F, Taser OF. High tibial osteotomy with Puddu plate for the treatment of varus gonarthrosis. Knee Surg Sports Traumatol Arthrosc. 2006;14(10):948-54

17. Kessler OC, Jacob HA, Romero J. Avoidance of medial cortical fracture in high tibial osteotomy: improved technique. Clin Orthop Relat Res. 2002(395):180-5 